\title{
Micturition requires active opening of the posterior urethral wall by directional striated muscles
}

\author{
(D) PETER PETROS
}

School of Engineering, University of Western Australia

\section{ABSTRACT}

The video demonstrates that the current concept of total pelvic floor relaxation preceding micturition is only partly correct. It is only the anterior part of pelvic floor which relaxes. The posterior muscles stretch the bladder/urethral smooth muscle backwards to tension it, prior to active opening of the posterior urethral wall by the downward angulation of the anterior border of levator plate by the conjoint longitudinal muscle of the anus. This action expands the diameter of the urethra, vastly reducing the resistance to flow and therefore, the head of pressure required to be generated by the detrusor to empty the bladder.

Keywords: Micturition video; Integral Theory; active opening; striated muscle

\section{INTRODUCTION}

Text adapted from: Petros P, Lynch W, Bush M. Surgical repair of uterosacral/cardinal ligaments in the older female using the tissue Fixation system improves symptoms of obstructed micturition and residual urine. Pelviperineology 2015;34:112-116.

Inability to adequately evacuate the bladder is a major source of repeated urinary infection and pathology. ${ }^{1}$ Catheter-associated urinary tract infection (UTI) is the most common nosocomial infection, accounting for $>1$ million cases in hospitals and nursing homes. The risk of UTI increases with increasing duration of catheterization. In non-institutionalized elderly populations, UTIs are the second most common form of infection, accounting for nearly $25 \%$ of all infections with a cost of 1 billion dollars p.a. ${ }^{1}$ The traditional view of the mechanism of micturition was described by Messelink et al: " "The pelvic floor muscles must relax in order to remove the passive continence mechanisms, thereby favouring normal micturition". A recent
Review of voiding dysfunction ${ }^{2,3}$ shed little light on the problem. It stated, "There remains a lack of consensus regarding a precise diagnosis and definition of voiding abnormalities in women". The Review's statement of causation ${ }^{2}$ was limited to "detrusor underactivity and outflow obstruction which could be either physiological or iatrogenic". Two studies reporting improvement of bladder emptying following cystocele and fascial repair were mentioned, but no anatomical explanations were forwarded as to why. ${ }^{2}$ We believe that the answer to these conundra is to be found in urethral resistance to urine flow which is exponentially determined and is instantaneously modified by an external striated muscle mechanism first described in $1990 .{ }^{4}$

Micturition Video: https://www.youtube.com/watch?v=eiF4G1 mk6EA\&feature=youtu.be

This mechanism, since validated with electromyography and video X-ray studies stretches open the posterior urethral walls during micturition, 5,6 Figure 1 and 2, and is in turn ultimately dependent on competent posterior suspensory ligaments 
in the position of the cervix (CX), Figure 1.,5 The external opening mechanism, Figure 1 and 2, was described as follows: immediately prior to commencement of voiding, the forward closure vector ( $\mathrm{m}$. pubococcygeus) relaxes; relaxation of $\mathrm{m}$. pubococcygeus releases the closure pressure of the hammock on the posterior urethral wall, thereby freeing the posterior vectors (levator plate and the conjoint longitudinal muscle of the anus, arrows, Figure 1, to actively open the urethra prior to detrusor contraction; this causes the urethra to funnel, exponentially lowering the resistance to flow immediately prior to the expulsive action of the detrusor. ${ }^{6}$ According to,${ }^{4}$ the keystone of this mechanism is the requirement for firm anchoring points for the downward opening vector, the uterosacral/cardinal ligaments (CL/USL) at CX, Figure 1: the downward opening vector (white arrow, Figure 1) contracts against the CL/USL: if the USL is loose, the vector weakens: ${ }^{7}$ the vector cannot open out the posterior urethral wall; the detrusor contracts against an unopened urethra and therefore, a high urethral resistance; a higher detrusor pressure is required for expulsion, Figure 3; the patient will have bladder emptying difficulties because of greatly increased resistance to flow. ${ }^{8}$ Resistance to flow is highly sensitive to this opening mechanism, as it is exponentially determined (Poiseuille's Law). For non-laminar flow, it is approximately inversely related to the $4^{\text {th }}$ power of the radius $(r){ }^{8}$ With reference Figure 1, there appears to be almost doubling

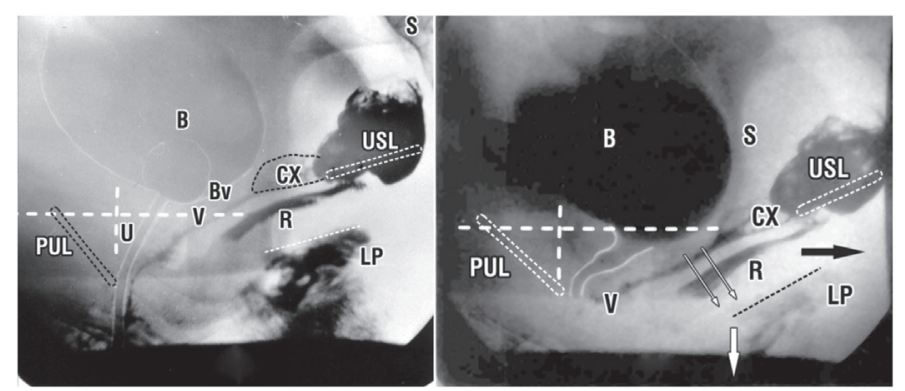

Figure 1. Normal patient. X-rays at rest (left) and during micturition (right), samepatient in sitting position. At rest, slow twitch contractions angulate bladder (B), urethra (U), vagina (V) and rectum (R) around the insertion of the pubourethral ligament (PUL) at midurethra. $10 \mathrm{ml}$ radiopaque material has been injected into the levator plate (LP) vagina and rectum. Vertical and horizontal broken lines indicate bony co-ordinates. During micturition (right figure), the urethra has moved backwards from the vertical co-ordinate, suggesting relaxation of the forward vector. Vagina and rectum appear to have been stretch backwards by a backward vector (black arrow). The anterior part of LP has been angulated downwards apparently by the downward vector (white arrow) acting against the CX/USL complex. The backward/downward vectors (thin diagonal arrows) create a diagonal vector force which seems to be pulling open the posterior urethral wall.

B: Bladder; U: Urethra; V: Vagina; R: Rectum; PUL: Pubourethral ligament; LP: Levator plate; CX: Cervix; USL: Uterosacral ligament; S: Sacrum of the urethral diameter during micturition. The pressure flow relationship as determined by direct laboratory measurement and computer modelling is shown in Figure $3 .{ }^{8}$ At a diameter of $3.5 \mathrm{~mm}$, a pressure head of approximately $170 \mathrm{~cm} \mathrm{H}_{2} \mathrm{O}$ is required to achieve a flow rate of $50 \mathrm{ml} / \mathrm{sec}$, Figure 3. If the urethra can be opened out from $3.5 \mathrm{~mm}$ to $6 \mathrm{~mm}$ by the proposed external mechanism, the head of pressure required for a $50 \mathrm{ml} / \mathrm{sec}$ flow falls to $20 \mathrm{~cm} \mathrm{H}_{2} \mathrm{O}$.
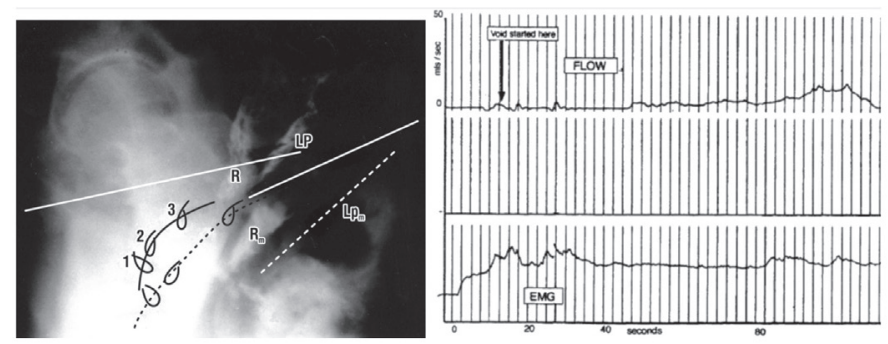

Figure 2. Micturition X-ray superimposed on resting X-ray (left side), patient sitting. Vascular clips have been applied to the midurethra "1". Bladder neck "2" and bladder base "3". Radio-opaque dye has been injected into the levator plate "LP", which has been angulated downwards during micturition, as has the rectum " $R$ ", which has $10 \mathrm{ml}$ of barium paste. Broken lines indicate position of organs during micturition. Subscript " $\mathrm{m}$ " indicates the position of rectum "R" and levator plate "LP" during micturition. Surface EMG (right side) Surface EMG cylinder placed in the posterior fornix of the vagina simultaneous with uroflowmetry. EMG shows that muscle contraction preceded urine flow.

LP: Levator plate; R: Rectum; EMG: Electromyography

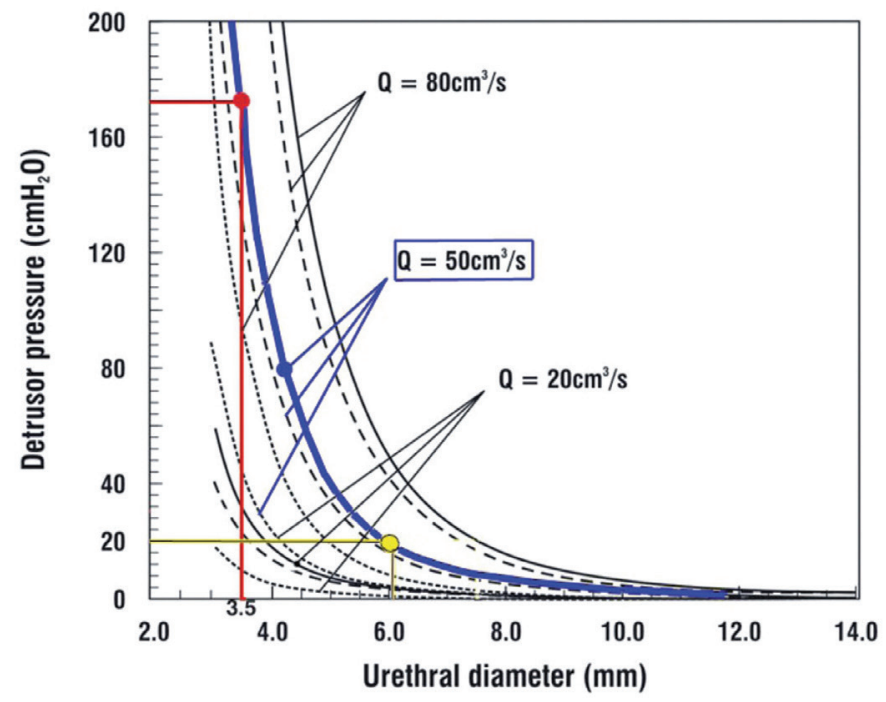

Figure 3. Pressure flow graph - detrusor pressure as a function of urethral diameter for urethral length of $4 \mathrm{~cm}$ at flow rates of 20, 50, $80 \mathrm{ml} / \mathrm{sec}$ (8). Total resistance to flow (unbroken line) - Frictional component .............. Dynamic component - - - - - -. For a flow rate of $50 \mathrm{ml} / \mathrm{sec}$ (blue line), increasing the diameter of the urethra from $3.5 \mathrm{~mm}$ to $6 \mathrm{~cm}$, reduces the head of pressure required to empty from approximately $170 \mathrm{~cm} \mathrm{H}_{2} \mathrm{O}$ to $20 \mathrm{~cm} \mathrm{H}_{2} \mathrm{O}$.

Q: Flow $\left(\mathrm{cm}^{3} / \mathrm{s}\right)$ 


\section{Ethics}

Peer-review: Externally peer-reviewed.

\section{DISCLOSURES}

Conflict of Interest: The author has no conflicts of interest.

Financial Disclosure: The author declared that this study has received no financial support.

\section{REFERENCES}

1. Foxman B. Epidemiology of urinary tract infections: incidence, morbidity, and economic costs. Am J Med 2002; 113: 5-13.

2. Messelink B, Benson T, Berghmans B, et al. Standardization of terminology of pelvic floor muscle function and dysfunction: report from the pelvic floor clinical assessment group of the International Continence Society. Neurourol Urodyn 2005; 24: 374-380.
3. Robinson D, Staskin D, Laterza RM, Koelbl H. Defining female voiding dysfunction: ICI-RS 2011. Neurourol Urodyn 2012; 31: 313-316.

4. Petros PE, Ulmsten UI. An integral theory of female urinary incontinence. Experimental and clinical considerations. Acta Obstet Gynecol Scand Suppl 1990; 153: 7-31.

5. Petros PE, Ulmsten U. Role of the pelvic floor in bladder neck opening and closure I: muscle forces. Int Urogynecol J Pelvic Floor Dysfunct 1997; 8: 74-80.

6. Papa Petros PE, Ulmsten U. Role of the pelvic floor in bladder neck opening and closure II: vagina. Int Urogynecol J Pelvic Floor Dysfunct 1997; 8: 69-73.

7. Gordon AM, Huxley AF, Julian FJ. The variation in isometric tension with sarcomere length in vertebrate muscle fibres. J Physiol 1966; 184: 170-192.

8. Bush MB, Petros PE, Barrett-Lennard BR. On the flow through the human female urethra. J Biomech 1997; 30: 967-969. 